\title{
Risk of subsequent fracture and mortality within 5 years after a non-vertebral fracture
}

\author{
K. M. B. Huntjens • S. Kosar • T. A. C. M. van Geel • \\ P. P. Geusens $\cdot$ P. Willems $\cdot$ A. Kessels $\cdot$ B. Winkens . \\ P. Brink $\cdot$ S. van Helden
}

Received: 6 July 2009 / Accepted: 14 January 2010 /Published online: 17 February 2010

(C) The Author(s) 2010. This article is published with open access at Springerlink.com

\begin{abstract}
Summary The absolute 5-year risk of subsequent nonvertebral fractures (NVFs) in 1,921 patients presenting with a NVF was $17.6 \%$ and of mortality was $32.3 \%$. These risks were highest within the first year, indicating the need to study which reversible factors can be targeted to immediately minimise subsequent fracture risk and mortality.

Introduction NVFs are the most frequent clinical fractures in patients presenting at the emergency unit because of a clinical fracture. The aim of the study was to determine the 5 -year absolute risk (AR) of subsequent NVF and mortality in patients at the time they present with a NVF.

Methods Between 1999 and 2001, 1,921 consecutive patients $50+$ years from a level 1 trauma centre were included. All NVFs were confirmed on radiograph reports,
\end{abstract}

Kirsten M. B. Huntjens and Sevginur Kosar contributed equally to this work.

K. M. B. Huntjens $(\bowtie) \cdot S$. Kosar $\cdot$ P. Brink $\cdot$ S. van Helden Department of Trauma Surgery,

Maastricht University Medical Centre,

P. Debyelaan 25, P.O. Box 5800, 6202 AZ Maastricht,

The Netherlands

e-mail:k.huntjens@ah.unimaas.nl

K. M. B. Huntjens · S. Kosar · T. A. C. M. van Geel •

B. Winkens $\cdot$ P. Brink $\cdot$ S. van Helden

School for Public Health and Primary Care (CAPHRI),

Maastricht, The Netherlands

T. A. C. M. van Geel

Department of General Practice,

Maastricht University Medical Centre,

P.O. Box 616, 6200 MD Maastricht, The Netherlands

P. P. Geusens

Department of Internal Medicine/Rheumatology,

Maastricht University Medical Centre,

Maastricht, The Netherlands and mortality was checked in the national obituary database. Available potential risk factors for a subsequent NVF and mortality (age, sex and baseline fracture location: major-hip, pelvis, multiple ribs, proximal tibia/humerus and distal femur; minor-all others) were expressed as hazard ratios (HR) with $95 \%$ confidence intervals (CI) using multivariable Cox regression analysis.

Results The AR for a subsequent NVF was $17.6 \%$ and was related to age (HR per decade, 1.44; 95\% CI, 1.29-1.60). The AR for mortality was $32.3 \%$ and was related to age (HR per decade, 2.59; 95\%CI, 2.37-2.84), male sex (HR, 1.74 ; $95 \% \mathrm{CI}, 1.44-2.10$ ), major fracture at baseline (HR, 5.56; 95\%CI, 3.48-8.88; not constant over time) and subsequent fracture (HR, $1.65 ; 95 \% \mathrm{CI}, 1.33-2.05)$. The highest risks were found within the first year (NVFs, 6.4\%;

\section{P. P. Geusens}

Biomedical Research Institute, University Hasselt,

Hasselt, Belgium

A. Kessels

KEMTA (Klinische Epidemiologie en Medical

Technology Assessment),

Maastricht, The Netherlands

P. Willems

Department of Othopaedic Surgery,

Maastricht University Medical Centre,

Maastricht, The Netherlands

B. Winkens

Department of Methodology and Statistics,

Maastricht University Medical Centre,

Maastricht, The Netherlands 
mortality, $12.2 \%$ ) and were related to age and, in addition, to baseline fracture location for mortality.

Conclusions Within 5 years after an initial NVF, nearly one in five patients sustained a subsequent NVF and one in three died. One third of subsequent NVFs and mortality occurred within 1 year, indicating the need to study which reversible factors can be targeted to immediately prevent subsequent fractures and mortality.

Keywords Fracture incidence $\cdot$ Fracture risk $\cdot$ Mortality . Non-vertebral fractures · Timing

\section{Introduction}

A history of non-vertebral fracture (NVF) is associated with a doubling of the risk of a subsequent fracture, and the subsequent fracture risk is quadrupled after a vertebral fracture $[1,2]$. This subsequent fracture risk is not constant over time and is driven by the high, three to fivefold increase in the years immediately after a first fracture, followed by a gradual waning off later on [3]. This has been shown for repeat morphometric vertebral fractures [4], subsequent clinical spine, forearm and hip fractures in patients who were hospitalised with a vertebral fracture [5], repeat low-trauma fractures in subjects older than 60 years [6], repeat clinical vertebral and non-vertebral fractures from menopause onwards $[3,7,8]$ and repeat hip fractures [9]. As a result, it has been shown in long-term follow-up studies that $40 \%$ to $50 \%$ of all subsequent fractures occur within 3 to 5 years after a first fracture. The clinical implication is that patients older than 50 years presenting with a fracture need immediate attention to reduce reversible risk factors of a subsequent fracture. This indicates that to undertake immediate care in fracture patients is necessary, such as the Fracture Liaison Service, the involvement of a fracture nurse and other initiatives in the field of post-fracture care [10-13]. It also indicates that treatment, which has been shown to reduce fracture risk within short term, should be started as soon as possible in patients with a high fracture risk [14].

An increased risk of mortality has been documented after hip, vertebral and several non-hip, non-vertebral fractures [15]. Similar to subsequent fracture risk, this increase in mortality is higher immediately after fracture than later on. In women and men older than 60 years, nearly $90 \%$ of excess deaths related to fracture over the 18 years of observation occurred in the first 5 years.

Of the 5-year post-fracture excess mortality, approximately one third of deaths were associated to hip, vertebral and non-hip, non-vertebral fractures, respectively. The major causes of death were related to cardiovascular and respiratory comorbidity and infections [15].
NVFs are the most frequent fractures in patients presenting at the emergency unit because of a clinical fracture [8]. There is therefore an increasing interest on the role of drug intervention to reduce the risk of NVFs [16] and subsequent mortality [17]. To our knowledge, this is the first study analysing all consecutive patients older than 50 years of age presenting with a NVF during a 5-year follow-up. The aim of the present study was to determine the 5-year absolute risk (AR) of subsequent NVF and mortality after a NVF.

\section{Materials and methods}

\section{Recruitment of patients}

In this retrospective study, the hospital database code (International Classification of Disease, ICD-9) for fractures was used to recruit patients. All fractures reported in the patients' medical files were radiographically confirmed. Only subsequent fractures that are reported in the same hospital database were used for the follow-up analyses. Whether patients were deceased during follow-up was confirmed using the national obituary database. Inclusion criteria for this study were the following: (1) age $\geq 50$ years, (2) a recent NVF between January 1999 and December 2001 and (3) living in the postal code area of Maastricht. Patients were excluded if they had sustained a pathological fracture. Vertebral fractures were not taken into consideration. The ICD-9 was used to classify clinical fractures into 15 categories: skull, vertebra, clavicle, thorax, pelvis, humerus, forearm, wrist, hand, hip, femur, patella, tibia/ fibula, ankle or foot. These fractures were further analysed according to fracture location (humerus, wrist and hip) and grouping of several locations: other, multiple simultaneous fractures belonging to the six main NVFs (wrist, leg, humerus, hip, pelvis or clavicle) or not [16] and into major fractures (hip, pelvis, proximal tibia or humerus, multiple ribs and distal femur) and minor fractures (all other fractures) [18]. All groups are mutually exclusive and included all patients.

Available potential risk factors for subsequent fracture and mortality included age, sex and baseline fracture locations [6, 15]. In this paper, we only showed the Kaplan-Meier and Cox regression analyses with major vs. minor fractures as baseline fracture location. To create Table 1, we used the other classifications as mentioned above.

\section{Statistical analysis}

Univariable Kaplan-Meier curves and univariable, multivariable and time-dependent Cox regression analyses were 
Table 1 Patients according to baseline fracture location

\begin{tabular}{lccc}
\hline Baseline fracture location & Men, $N=488(\%)$ & Women, $N=1,433(\%)$ & All $N=1,921(\%)$ \\
\hline Humerus & $38(7.8)$ & $184(12.8)$ & $222(11.6)$ \\
Wrist & $69(14.1)$ & $433(30.2)$ & $502(26.1)$ \\
Hip & $115(23.6)$ & $354(24.7)$ & $469(24.4)$ \\
Other & $203(41.6)$ & $358(25.0)$ & $561(29.2)$ \\
Multiple & $63(12.9)$ & $104(7.3)$ & $167(8.7)$ \\
6 main NVFs & $341(69.9)$ & $1,211(84.5)$ & $1,552(80.8)$ \\
No main NVFs & $147(30.1)$ & $222(15.5)$ & $369(19.2)$ \\
Major & $214(43.9)$ & $651(45.4)$ & $865(45.0)$ \\
Minor & $274(56.1)$ & $782(54.6)$ & $1,056(55.0)$ \\
\hline
\end{tabular}

performed to determine the contribution of risk factors (age, sex and location of the baseline fracture) to the incidence of subsequent NVFs and mortality. Follow-up time was defined as time between first fracture and subsequent fracture, death or end of the study period of 5 years. With respect to mortality, the follow-up time was defined as time between first fracture and death or end of the study period. Hazard ratios (HR) and $95 \%$ confidence intervals $(95 \% \mathrm{CI})$ were reported. Two-tailed $p<0.05$ was considered significant. The Schoenfeld residuals were used to check the assumptions of proportionality. If violated, then we used the time-dependent Cox regression analysis to represent the profile of the HR over time. Linearity was checked for age. SPSS 15.0 for windows (SPSS Inc., Illinois, USA) was used to process the data.

\section{Results}

A total of 1,921 patients aged over 50 years were included, 1,433 women and 488 men. Women were significantly older than men (women $73.5 \pm 11.5$ years and men $67.1 \pm$ 12.2 years, $p<0.001)$. The majority of the baseline fractures occurred at the ulna/radius (number of patients $=502$, $26.1 \%$ ), hip (number of patients $=469,24.4 \%$ ) and other (number of patients $=561,29.2 \%$; Table 1 ).

The patients can be categorised into the following four groups: patients who died without $(n=509)$ or after a subsequent NVF $(n=111)$ and patients still alive after 5 years of follow-up with $(n=227)$ or without a subsequent NVF ( $n=1,074$; Fig. 1) during a total of 7,685 patientyears. Clearly, the most common outcome 5 years after a NVF is to be alive without a subsequent fracture (in 55.9\% of patients; Fig. 1).

\section{Subsequent fractures}

During the 5-year follow-up period, 338 patients had 379 subsequent $\mathrm{NVFs}$, indicating an $\mathrm{AR}$ of $17.6 \%(95 \% \mathrm{CI}$, 15.9-19.3; Fig. 1).
In univariable analysis, women sustained significantly more subsequent fractures than men $(19.3 \%$ vs. $12.7 \%, p=0.001$; $\mathrm{HR}, 1.54 ; 95 \% \mathrm{CI}, 1.17-2.03)$. Also, increasing age (HR, per decade, $1.49 ; 95 \% \mathrm{CI}, 1.36-1.64)$ and major baseline fracture location (HR 1.60; 95\%CI, 1.29-1.98) contributed in univariable analysis to subsequent fracture risk (Fig. 2).

Hazard ratios were similar when baseline finger and toe fractures were excluded in the analysis (data not shown). In multivariable analysis, only age (HR per decade, 1.44; 95\% CI, 1.29-1.60) remained a significant contributor.

\section{Mortality}

During 5 years of follow-up, a total of 620 patients died, indicating an $\mathrm{AR}$ of $32.2 \%(95 \% \mathrm{CI}, 30.1-34.3)$. This number consisted of 468 (32.7\%) women and 152 men (31.1\%). Univariable analysis showed a significant contribution of age and baseline fracture location to mortality incidence ( $p<0.001$; Fig. 2). To evaluate whether patients with a subsequent fracture had an increased risk on mortality compared with patients without a subsequent fracture, we used the time-dependent Cox regression analysis. This showed, in univariable analysis, an association (HR, 2.48; 95\% CI, 2.00-3.07) between patients with a subsequent fracture and mortality compared with patients without a subsequent fracture.

In multivariable analysis, the incidence of mortality was higher in men (HR, 1.74; 95\%CI, 1.44-2.10) compared with

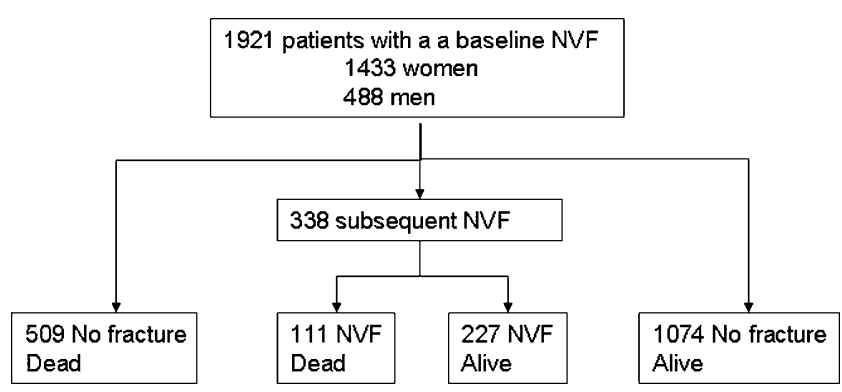

Fig. 1 Flowchart of patients included in the study 


\section{Subsequent fracture incidence}
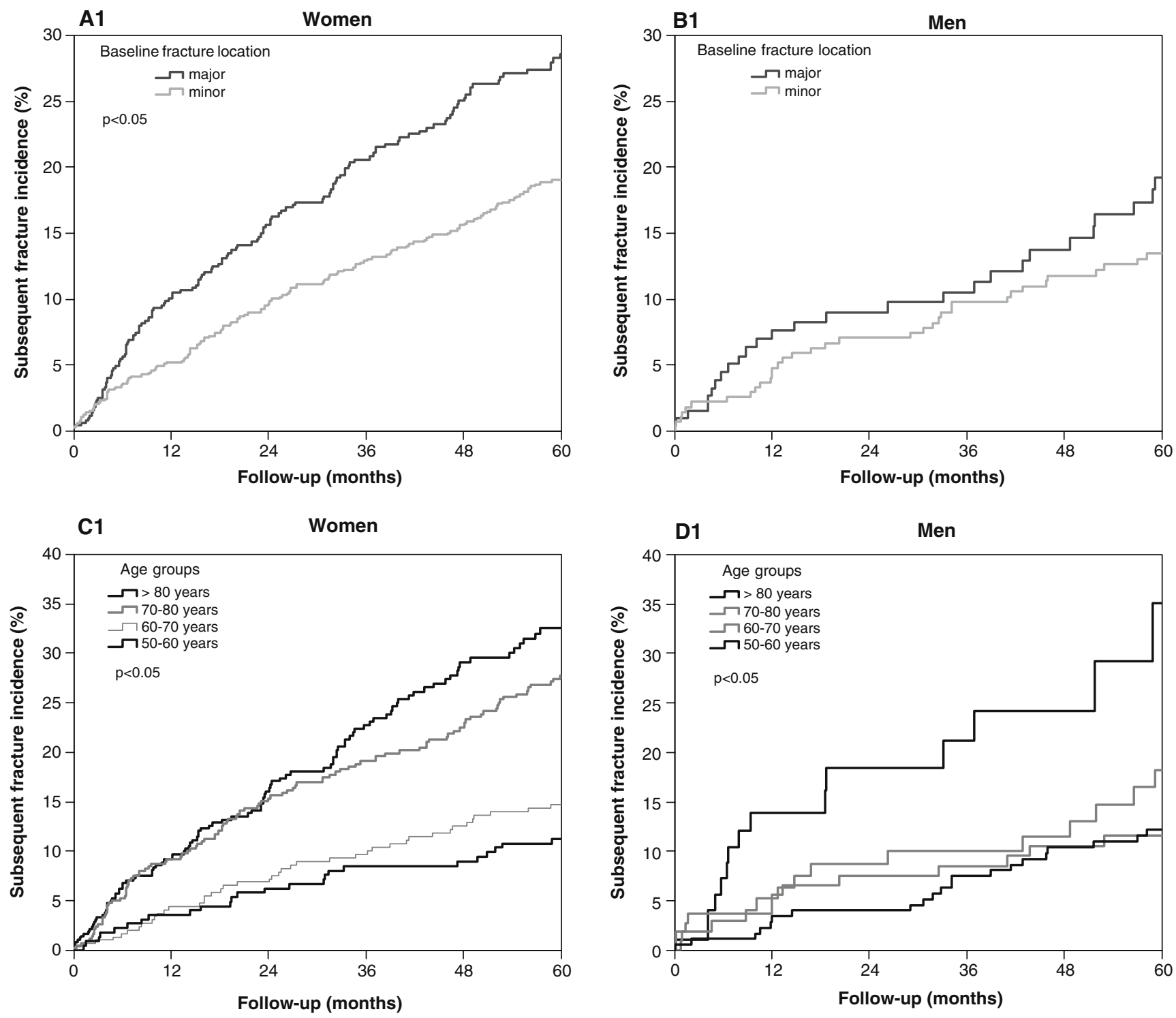

Fig. 2 Kaplan-Meier curves stratified by sex (univariable analysis). $A 1-B 1$ Subsequent fracture incidence by baseline fracture location. $C 1-D 1$ Subsequent fracture incidence by age in groups. $A 2-B 2$

Mortality incidence according to baseline fracture location. $C 2-D 2$ Mortality incidence according to age in groups. Values of $p$ for all comparisons were calculated with the use of the log-rank test

women, corrected for age and baseline fracture location. The HR of baseline fracture location (major/minor) was not consistent over time. Using time-dependent Cox regression, immediately after the baseline fracture, HR was $5.56(95 \%$ CI, 3.48-8.88) and declined at 37 months of follow-up to HR $1.27(95 \% \mathrm{CI}, 0.97=1.66 ; p=0.077)$ and increased slightly thereafter to approximately the HR at 12 months (Table 2). Overall results of Cox regression showed that age, male gender, a major fracture and a subsequent fracture at baseline were independent risk factors for mortality (Table 2).
Timing of subsequent NVF and mortality

Risk of subsequent NVF and mortality significantly changed over time (Fig. 3). The AR for subsequent NVF was $6.4 \%$ and progressively decreased to $3.3 \%$ in the fifth year (Fig. 3).

Of all the patients with a subsequent NVF, 36.4\% sustained a NVF within the first year. Clustering of fractures was found at all ages in women and men and in all subgroups of fractures.

The incidence of mortality was highest in the first year following the baseline fracture (12.2\%) and declined to $6.9 \%$ 


\section{Mortality incidence}
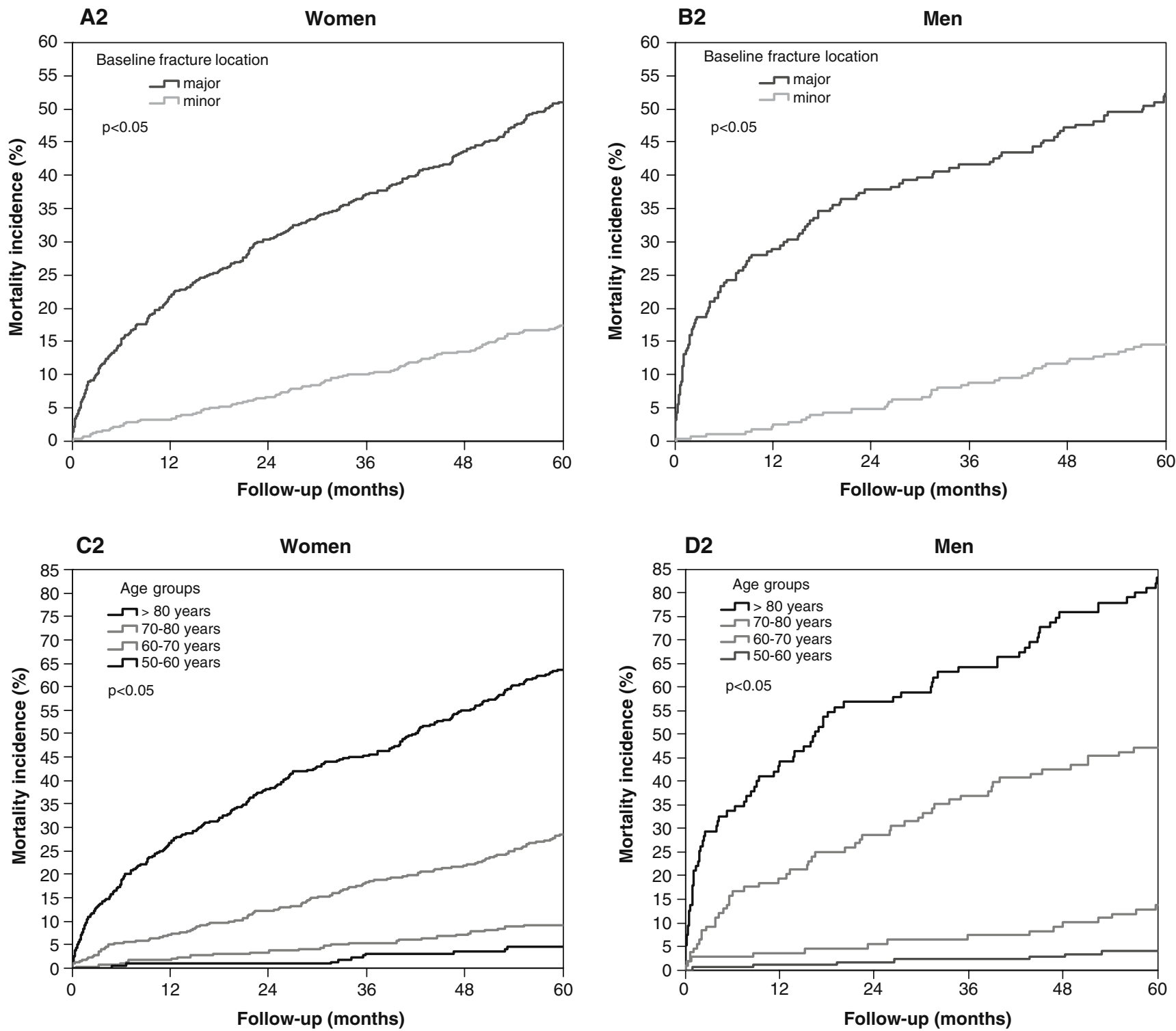

Fig. 2 (continued)

Table 2 Mortality incidence: multivariable Cox regression analysis with time-dependent covariates

\begin{tabular}{lllr}
\hline Variable & Hazard ratio & $95 \% \mathrm{CI}$ & $p$ value \\
\hline Sex men vs. women & 1.74 & $1.44-2.10$ & $<0.001$ \\
Age (per decade) & 2.59 & $2.37-2.84$ & $<0.001$ \\
Baseline fracture location (major vs. minor) & & & \\
0 months & 5.56 & $3.48-8.88$ & $<0.001$ \\
12 months & 2.44 & $1.90-3.14$ & $<0.001$ \\
24 months & 1.49 & $1.13-1.96$ & 0.004 \\
36 months & 1.27 & $0.97-1.66$ & 0.083 \\
48 months & 1.50 & $1.14-1.97$ & 0.004 \\
60 months & 2.47 & $1.41-4.33$ & 0.002 \\
Patients with a subsequent fracture vs. patients & 1.65 & $1.33-2.05$ & $<0.001$ \\
without a subsequent fracture & & & \\
\hline
\end{tabular}


Fig. 3 Subsequent risk of fracture and mortality cluster in time. Patients at risk divided into 5 years of the follow-up period. Fractures per year were cumulative in survivors
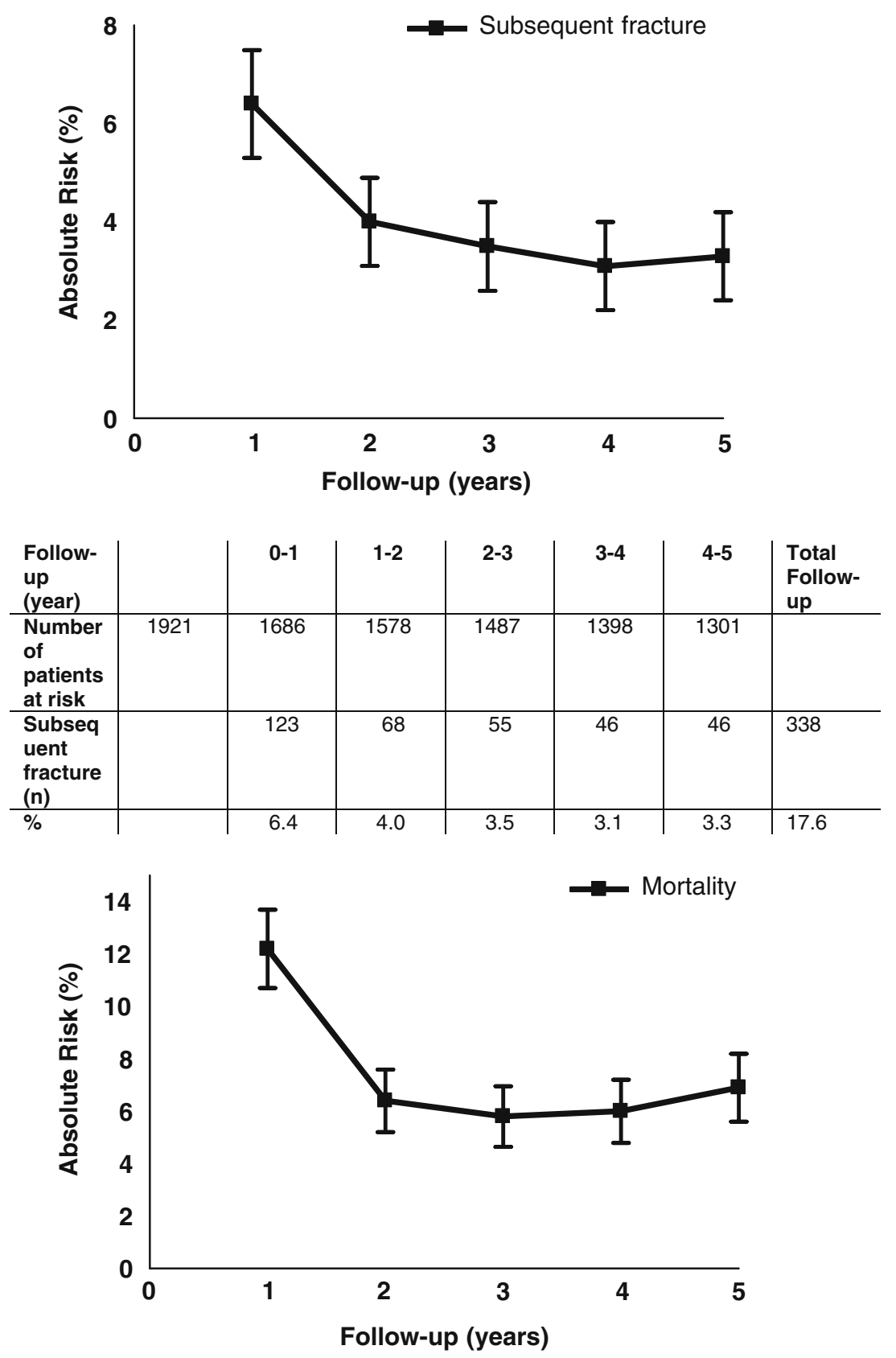

\begin{tabular}{l|l|c|c|c|c|c|l}
$\begin{array}{l}\text { Follow- } \\
\text { up } \\
\text { (year) }\end{array}$ & & $\mathbf{0 - 1}$ & $\mathbf{1 - 2}$ & $\mathbf{2 - 3}$ & $\mathbf{3 - 4}$ & $\mathbf{4 - 5}$ & $\begin{array}{l}\text { Total } \\
\text { Follow- } \\
\text { up }\end{array}$ \\
\hline $\begin{array}{l}\text { Number } \\
\text { of } \\
\text { patients } \\
\text { at risk }\end{array}$ & 1921 & 1686 & 1578 & 1487 & 1398 & 1301 & \\
\hline $\begin{array}{l}\text { Mortality } \\
\text { (n) }\end{array}$ & & 235 & 108 & 91 & 89 & 97 & 620 \\
\hline$\%$ & & 12.2 & 6.4 & 5.8 & 6.0 & 6.9 & 32.3
\end{tabular}

in the fifth year (Fig. 3). Of all subsequent mortality, 37.9\% occurred within the first year. Of the patients who sustained a hip fracture, the 1-year mortality was $40 \%$ in men and $29 \%$ in women. At the end of the follow-up period, $302(65 \%)$ of the hip fracture patients at baseline were deceased.

\section{Discussion}

Based on hospital databases for radiographically diagnosed fractures to ascertain fractures and the national obituary, the AR of sustaining a new NVF within 5 years 
after a NVF was $17.6 \%$ and $32.3 \%$ for mortality. Until today, no data have been published regarding subsequent fracture risk and mortality in a patient population with all clinical fractures (NVF) of 50 years and over with a 5-year follow-up period. Moreover, there are no guidelines which recommend evaluating all these patients investigated in this research.

Remarkably, after multivariable analysis, patients sustaining a minor fracture had a similar risk to a subsequent fracture as patients with a major fracture at baseline even after a hip fracture. In addition, the same was true between sexes: After correcting for age, subsequent fracture rate was similar between men and women, as found by Center et al. [6]. Even patients with a wrist fracture at baseline had an AR of a subsequent fracture of $17.9 \%$ within 5 years of follow-up. From a clinical point of view, these results indicate that fracture prevention should be considered after any fracture. Increasing age was the most important factor for a subsequent fracture corrected for sex and baseline fracture location. Only three variables (age, gender and fracture location) were available, and not surprisingly, age was the most predictive factor, as in most other fracture prediction models. Over one third $(36.4 \%)$ of the patients sustained a subsequent NVF within the first year after their baseline fracture. Previous studies reported similar findings. In our own previous study, we found an absolute risk of $10.8 \%$ for sustaining any clinical subsequent fracture within 2 years after baseline fracture, with $60 \%$ occurring in the first year after the baseline fracture [8]. Van Geel et al. [3] found a RR of 5.3 of subsequent fracture compared with patients without a subsequent fracture.

Similar results were reported after vertebral fractures [19]. Center et al. showed that $41 \%$ of the women and $52 \%$ of the men sustained their subsequent fracture within the first 2 years after the initial fracture. The aim of this study was not to compare subsequent fracture incidence with first fracture incidence, as we already have shown in a population-based study in post-menopausal women between ages 45 and 90 years from the same region that the 1 -year incidence of all first fractures was $1.0 \%$. We recalculated the risk of only a first NVF which was $0.9 \%$ (excluding all patients with vertebral fractures). In that study, the first year subsequent fracture incidence was $6.0 \%$, almost equal as in our study (6.8\%) [3].

During the study, almost one in three patients died. Our results confirm previous findings by others that mortality is associated with increasing age, male gender and baseline fracture location in a multivariable model even at the age of 50 years and over [15, 18, 20-27].

There are some potential limitations to this study. First, due to the retrospective design of this study, we could have missed subsequent fractures which had occurred outside the recruitment region of the hospital. In an earlier study, $<1 \%$ of all patients presenting at the Emergency Department were from outside the hospital region, indicating that $<1 \%$ of fractures could have been missed [8]. All fractures in the hospital are coded (ICD-9) and stored in the hospital database. Second, vertebral fractures were excluded because of difficulty with verification of timing of these fractures. Third, we have no data on the trauma mechanism. In earlier studies, we have shown that about $20 \%$ of clinical fractures are not resulting from a fall from maximum standing height or lesser trauma [28]. However, Mackay et al. [29] have shown that the risk of subsequent fractures is similar after high- and low-energy trauma. There are no data available for mortality after high- and low-energy trauma in fractures.

Fourth, there are no data on the cause of death. We therefore cannot correlate if these deaths are directly related to the previous fracture or the subsequent fracture. The enhanced mortality could be a sign of poor health or other underlying conditions. Further studies will be necessary to examine to what degree bone and extraskeletal risks are predictive of subsequent fractures and mortality. Others have shown that bone, fall and general health-related factors could be involved [15].

In conclusion, we found that within 5 years after an initial NVF, nearly one in five patients sustained a subsequent NVF and one in three died. One third of subsequent NVFs and mortality occurred within 1 year, indicating the need to study which reversible factors can be targeted to immediately prevent subsequent fractures and mortality.

\section{Conflict of interest None.}

Open Access This article is distributed under the terms of the Creative Commons Attribution Noncommercial License which permits any noncommercial use, distribution, and reproduction in any medium, provided the original author(s) and source are credited.

\section{References}

1. Kanis JA, Johnell O, De Laet C, Johansson H, Oden A, Delmas P, Eisman J, Fujiwara S, Garnero P, Kroger H, McCloskey EV, Mellstrom D, Melton LJ, Pols H, Reeve J, Silman A, Tenenhouse A (2004) A meta-analysis of previous fracture and subsequent fracture risk. Bone 35:375-382

2. Klotzbuecher CM, Ross PD, Landsman PB, Abbott TA 3rd, Berger M (2000) Patients with prior fractures have an increased risk of future fractures: a summary of the literature and statistical synthesis. J Bone Miner Res 15:721-739

3. van Geel TA, van Helden S, Geusens PP, Winkens B, Dinant GJ (2009) Clinical subsequent fractures cluster in time after first fractures. Ann Rheum Dis 68:101-104

4. Lindsay R, Silverman SL, Cooper C, Hanley DA, Barton I, Broy SB, Licata A, Benhamou L, Geusens P, Flowers K, Stracke H, 
Seeman E (2001) Risk of new vertebral fracture in the year following a fracture. JAMA 285:320-323

5. Johnell O, Oden A, Caulin F, Kanis JA (2001) Acute and longterm increase in fracture risk after hospitalization for vertebral fracture. Osteoporos Int 12:207-214

6. Center JR, Bliuc D, Nguyen TV, Eisman JA (2007) Risk of subsequent fracture after low-trauma fracture in men and women. Jama 297:387-394

7. van Geel AC, Geusens PP, Nagtzaam IF, Schreurs CM, van der Voort DJ, Rinkens PE, Kester AD, Dinant GJ (2006) Timing and risk factors for clinical fractures among postmenopausal women: a 5-year prospective study. BMC Medicine 4:24

8. van Helden S, Cals J, Kessels F, Brink P, Dinant GJ, Geusens P (2006) Risk of new clinical fractures within 2 years following a fracture. Osteoporos Int 17:348-354

9. Ryg J, Rejnmark L, Overgaard S, Brixen K, Vestergaard P (2009) Hip fracture patients at risk of second hip fracture-a nationwide population-based cohort study of 169, 145 cases during 1977 2001. J Bone Miner Res 24:1299-1307

10. Chevalley T, Hoffmeyer P, Bonjour JP, Rizzoli R (2002) An osteoporosis clinical pathway for the medical management of patients with low-trauma fracture. Osteoporos Int 13:450-455

11. Gallacher SJ, Gallagher AP, McQuillian C, Mitchell PJ, Dixon T (2007) The prevalence of vertebral fracture amongst patients presenting with non-vertebral fractures. Osteoporos Int 18:185192

12. van Helden S, Cauberg E, Geusens P, Winkes B, van der Weijden T, Brink P (2007) The fracture and osteoporosis outpatient clinic: an effective strategy for improving implementation of an osteoporosis guideline. J Eval Clin Pract 13:801-805

13. van Helden S, van Geel AC, Geusens PP, Kessels A, Nieuwenhuijzen Kruseman AC, Brink PR (2008) Bone and fall-related fracture risks in women and men with a recent clinical fracture. $\mathrm{J}$ Bone Jt Surg Am 90:241-248

14. Geusens PP, Roux CH, Reid DM, Lems WF, Adami S, Adachi JD, Sambrook PN, Saag KG, Lane NE, Hochberg MC (2008) Drug Insight: choosing a drug treatment strategy for women with osteoporosis - an evidence-based clinical perspective. Nature Clinical Practice 4:240-248

15. Bliuc D, Nguyen ND, Milch VE, Nguyen TV, Eisman JA, Center JR (2009) Mortality risk associated with low-trauma osteoporotic fracture and subsequent fracture in men and women. Jama 301:513-521

16. Sebba A (2009) Comparing non-vertebral fracture risk reduction with osteoporosis therapies: looking beneath the surface. Osteoporos Int 20:675-686
17. Lyles KW, Colon-Emeric CS, Magaziner JS, Adachi JD, Pieper CF, Mautalen C, Hyldstrup L, Recknor C, Nordsletten L, Moore KA, Lavecchia C, Zhang J, Mesenbrink P, Hodgson PK, Abrams K, Orloff JJ, Horowitz Z, Eriksen EF, Boonen S (2007) Zoledronic acid and clinical fractures and mortality after hip fracture. N Engl J Med 357:1799-1809

18. Center JR, Nguyen TV, Schneider D, Sambrook PN, Eisman JA (1999) Mortality after all major types of osteoporotic fracture in men and women: an observational study. Lancet 353:878-882

19. Johnell O, Kanis JA, Oden A, Sernbo I, Redlund-Johnell I, Petterson C, De Laet C, Jonsson B (2004) Fracture risk following an osteoporotic fracture. Osteoporos Int 15:175-179

20. Cooper C, Atkinson EJ, Jacobsen SJ, O'Fallon WM, Melton LJ 3rd (1993) Population-based study of survival after osteoporotic fractures. Am J Epidemiol 137:1001-1005

21. Johnell O, Kanis JA, Oden A, Sernbo I, Redlund-Johnell I, Petterson C, De Laet C, Jonsson B (2004) Mortality after osteoporotic fractures. Osteoporos Int 15:38-42

22. Cauley JA, Thompson DE, Ensrud KC, Scott JC, Black D (2000) Risk of mortality following clinical fractures. Osteoporos Int 11:556-561

23. Cummings SR, Melton LJ (2002) Epidemiology and outcomes of osteoporotic fractures. Lancet 359:1761-1767

24. Browner WS, Pressman AR, Nevitt MC, Cummings SR (1996) Mortality following fractures in older women. The study of osteoporotic fractures. Arch Intern Med 156:1521-1525

25. Shortt NL, Robinson CM (2005) Mortality after low-energy fractures in patients aged at least 45 years old. J Orthop Trauma 19:396-400

26. Piirtola M, Vahlberg T, Lopponen M, Raiha I, Isoaho R, Kivela SL (2008) Fractures as predictors of excess mortality in the aged-a population-based study with a 12-year follow-up. Eur J Epidemiol 23:747-755

27. Ensrud KE, Ewing SK, Taylor BC, Fink HA, Stone KL, Cauley JA, Tracy JK, Hochberg MC, Rodondi N, Cawthon PM (2007) Frailty and risk of falls, fracture, and mortality in older women: the study of osteoporotic fractures. J Gerontol 62:744-751

28. Dumitrescu B, van Helden S, ten Broeke R, NieuwenhuijzenKruseman A, Wyers C, Udrea G, van der Linden S, Geusens P (2008) Evaluation of patients with a recent clinical fracture and osteoporosis, a multidisciplinary approach. BMC Musculoskeletal Disorders 9:109

29. Mackey DC, Lui LY, Cawthon PM, Bauer DC, Nevitt MC, Cauley JA, Hillier TA, Lewis CE, Barrett-Connor E, Cummings SR (2007) High-trauma fractures and low bone mineral density in older women and men. Jama 298:2381-2388 